\title{
Refugiados e migrantes: interfaces entre integração social e políticas públicas
}

\section{Refugees and migrants: interfaces between social integration and public policies}

\author{
Joana Emilia Senger (orcid.org/0000-0003-4845-6966) ${ }^{1}$
}

\begin{abstract}
Resumo
O presente trabalho tem como objetivo geral compreender quais são as principais demandas no campo dos direitos humanos e da integração social de migrantes e refugiados residentes na região do Vale dos Sinos, no estado do Rio Grande do Sul, no sul do Brasil. Participaram deste estudo 14 refugiados e migrantes residentes da região. Eles foram acessados por meio de um projeto de extensão universitário e do método snowball. Foram utilizados, na coleta de dados, um questionário sociodemográfico e uma entrevista semiestruturada com perguntas abertas e fechadas. Os dados foram submetidos à estatística simples e à análise de conteúdo. A partir dos resultados, identificaram-se diversas dificuldades que vêm sendo enfrentadas pelos migrantes e refugiados, principalmente no que diz respeito à integração social dessa população, aspecto que acaba contribuindo para a vulnerabilidade social.
\end{abstract}

Palavras-chave: Refugiados. Migrantes. Saúde mental. Integração social. Psicologia Social.

\begin{abstract}
The present work aims to understand the main demands in the field of human rights and social integration of migrants and refugees living in the Vale do Sinos region, in the state of Rio Grande do Sul, in south of Brazil. A total of 14 refugees and migrants resident in the region participated in this study. They were accessed through a university extension project and through the snowball method. A sociodemographic questionnaire and a semistructured interview with open and closed questions were used in the data collection. The data were submitted to simple statistics and content analysis. Based on the results, several difficulties were identified that are being faced by migrants and refugees, especially regarding the social integration of this population, an aspect that ends up contributing to social vulnerability.
\end{abstract}

Keywords: Refugees. Migrants. Mental health. Social integration. Social Psychology.

\footnotetext{
${ }^{1}$ Universidade Feevale, Novo Hamburgo, Brasil. E-mail: joanasenger@hotmail.com.
} 
Apesar de o deslocamento humano em diversas regiões do planeta ter aumentado consideravelmente desde a década de 1990, para o Alto Comissariado das Nações Unidas para Refugiados (Acnur, 2016), esse crescimento se elevou nos últimos cinco anos. Diante disso, considera-se que as razões principais dessa tendência envolvem o prolongamento e o aumento da frequência das situações de conflito que causam os fluxos de refugiados e a falta de resolutividade em curto, médio e longo prazo para essas situações (Acnur, 2016).

Atualmente, uma em cada 113 pessoas no planeta é solicitante de refúgio, deslocada interna ou refugiada. Ao todo, existiam 65,3 milhões de pessoas deslocadas por guerras e conflitos até o fim de 2015, segundo o Alto Comissariado das Nações Unidas para Refugiados (Acnur, 2016). Somente no Brasil, um relatório realizado pelo Comitê Nacional para os Refugiados (Conare, 2016) apontou um aumento das solicitações de refúgio no país de $2.868 \%$ nos últimos cinco anos. Essas solicitações passaram de 966, em 2010, para 28.670, em 2015. Até 2010 haviam sido reconhecidos 3.904 refugiados, já em abril de 2016 o total chegou a 8.863, o que representa um aumento de $127 \%$ de refugiados reconhecidos, incluindo reassentados. Os estados que mais receberam solicitações de asilo em 2014 foram do sul do país (35\% dos pedidos), ou seja, os números são alarmantes (Conare, 2016).

Diante desse cenário, segundo o Acnur (2017), cabe diferenciar os estrangeiros em situação de refúgio e o migrante. No que se refere a distinções legais, utiliza-se o termo refugiado para as pessoas que são obrigadas a deixar seus países em função de fundado temor de perseguição por motivos de raça, religião, nacionalidade, por pertencer a um determinado grupo social ou por suas opiniões políticas. Cabe destacar que a legislação brasileira também reconhece como refugiadas as pessoas que saíram de seus países em função de conflitos armados, violação generalizada de direitos humanos e violência (Lei $n$. $9.474,1997)$. Além disso, o status de refúgio não pode ser atribuído às pessoas que cometeram crimes de guerra, contra a humanidade, contra a paz, crimes hediondos ou que participaram de atos terroristas ou do tráfico de drogas.

Já os migrantes são todas as pessoas que deixam seus países de origem com o objetivo de se estabelecer em outro país de forma temporária ou permanente. Os migrantes 
podem ter, entre outras, motivações sociais e econômicas, pois tentam escapar da pobreza ou do desemprego, buscando melhores condições de vida, maior acesso a trabalho, saúde e educação (Acnur, 2017). Segundo Gonçalves (2001), as migrações costumam figurar como o lado visível de fenômenos invisíveis. Aparecem muitas vezes como a superfície agitada de correntes subterrâneas e verdadeiros termômetros que, ao mesmo tempo, revelam e escondem transformações ocultas. O deslocamento está ligado a grandes e significativas mudanças, sejam elas econômicas, políticas, culturais ou sociais. Sendo assim, devemos pensar que quando o deslocamento se intensifica algo aconteceu ou está para acontecer, ou seja, há algo acontecendo por trás desses deslocamentos que também precisa de um olhar (Gonçalves, 2001). Diante disso, é importante ressaltar que não existe uma definição legal e uniforme para o termo migrante em âmbito internacional.

Diante de tantos conflitos mundiais, a Declaração Universal dos Direitos Humanos (DUDH) surge como uma via para garantir a proteção do homem. Essa declaração tem como diretrizes, além da proteção, prover a liberdade, a justiça e a paz no mundo. Pode-se dizer que os Direitos Humanos foram a primeira forma direta de contato do mundo com a questão do refúgio.

Diversos artigos podem servir de respaldo para que haja uma proteção em relação à população de refugiados, portanto, o direito ao asilo está diretamente ligado à segurança humana. Uma pessoa vítima de perseguição em seu país, por exemplo, não deve viver nele com medo e com privações, sendo assim, é de extrema importância que o país que ofereça asilo também ofereça segurança e condições de vida ao sujeito que está se submetendo ao refúgio (Moreira \& Gomes, 2012).

No que se refere à proteção social, apesar de o Brasil ter assumido o compromisso internacional de "fornecer proteção a refugiados que buscam sua integração e sustento, como qualquer cidadão brasileiro" (Acnur, 2017, p. 7), estudos recentes têm apontado para o despreparo do Estado brasileiro em acolher e garantir os direitos humanos dessa população (Padilla, 2013; Pussetti \& Brazzabeni, 2011; Sakho, Diop, Mboup \& Diadiou, 2015). Ressalta-se que desenvolver estudos que atribuam visibilidade para as demandas e para as vivências dessa população torna-se fundamental para a melhoria desse cenário. 
Sendo assim, este trabalho tem como objetivo apresentar uma caracterização e um levantamento das demandas de um grupo de migrantes e pessoas em situações de refúgio residentes no Vale dos Sinos, Rio Grande do Sul.

\section{Método}

Esta pesquisa tem caráter exploratório-descritivo (Gil, 2002) e utilizou o método misto, que utiliza a combinação de métodos qualitativos e quantitativos. Esse método é muito eficaz para pesquisas na área das ciências sociais e da saúde, visto que essas áreas costumam pesquisar problemas muito complexos (Creswell, 2010).

Os participantes do estudo foram acessados por meio de projeto de extensão universitária e, para atingir o número esperado de participantes, utilizou-se o método snowball, que prevê que os participantes iniciais indiquem outra pessoa para participar da pesquisa e assim sucessivamente até que o objetivo inicial seja atingido. Essa técnica permite que novos participantes sejam encontrados e, além disso, propicia uma aproximação com a população estudada (Baldin \& Munhoz, 2011).

Participaram deste estudo 14 pessoas em situação de refúgio ou migrante, todos do sexo masculino, com idade entre 23 e 40 anos $(M=29,2)$. Foram incluídos sujeitos com mais de 18 anos que tivessem o status de refugiado ou migrante, que estivessem morando no Brasil há mais de dois meses e residindo na região do Vale dos Sinos. Não foram incluídos sujeitos que não compreendiam os termos de participação por não falarem a língua portuguesa, que estavam a menos de um mês no Brasil e que tinham idade inferior a 18 anos.

Este projeto de pesquisa foi submetido ao Conselho de Ética em Pesquisa e aprovado pelo Parecer $n^{\circ} 63162016.9 .0000 .5348$. É importante ressaltar que os entrevistados foram identificados ao longo do trabalho por letras, que não condizem com a letra inicial de seus nomes verdadeiros.

Referentemente à coleta de dados, inicialmente foi feita uma parceria da pesquisadora com um projeto de extensão universitária que atende à população de 
refugiados e migrantes na região do Vale dos Sinos. A partir disso, realizou-se uma busca ativa de possíveis participantes por meio de abordagens de rua e indicações. A indicação dos participantes ocorreu pelo método snowball, sendo que o contato inicial foi feito por telefone ou por intermédio de uma abordagem presencial. Para a coleta de dados, foi utilizado um questionário sociodemográfico, que teve como objetivo conhecer os aspectos sociodemográficos para fazer um mapeamento da população e uma entrevista semiestruturada (Laville \& Dione, 1999).

Os indivíduos que aceitaram participar receberam o Termo de Consentimento Livre Esclarecido (TCLE), que foi lido em conjunto com o participante e assinado por ambas as partes, participante e pesquisador, permanecendo cada um com uma cópia. Na etapa seguinte, o questionário sociodemográfico foi aplicado, sendo gravado e transcrito.

Cabe destacar que o idioma e o acesso aos participantes constituíram uma limitação neste estudo. No caso do idioma, em certas situações a comunicação tornava-se bastante complicada, o que pode ter dificultado tanto a interpretação do participante sobre a pergunta quanto o entendimento da pesquisadora sobre a resposta. Já a aproximação pode ser tratada como uma limitação, visto que se sabe que há muitos outros migrantes e refugiados residentes na região, no entanto, muitos mostravam-se pouco disponíveis para participar da pesquisa. Isso ocorreu, em muitos casos, em função da dificuldade com o idioma, mas também por outras questões, como horário de trabalho ou acesso ao local para a realização da aplicação.

Os dados obtidos por meio do questionário passaram por uma análise de estatística simples, sendo assim, as respostas objetivas encontradas no questionário foram inseridas no programa Excel e calculadas por intermédio da manipulação do programa, originando gráficos. Em contrapartida, o conteúdo obtido pelas perguntas abertas foi transcrito na íntegra, depois da escuta das gravações e, em seguida, submetido à análise de conteúdo. Essa técnica possibilita a descrição do conteúdo manifesto e latente das comunicações. A análise de conteúdo é composta de três fases: na primeira, o pesquisador seleciona o material que deseja analisar; na segunda, explora e classifica esse material; e, na terceira, interpreta os dados (Gil, 2002). Os dados qualitativos foram categorizados e, 
posteriormente, associados aos dados quantitativos, tornando-se complementares, ampliando as possibilidades de discussão.

\section{Análise e discussão dos resultados}

Os dados obtidos por esta pesquisa permitiram a construção de 11 categorias, que serão apresentadas e discutidas a seguir, quais sejam: a) país de origem; b) status legal; c) estado civil e configurações familiares; d) religião; e) idioma; f) cidade de residência; g) escolaridade; h) ocupação no país de origem; i) ocupação no Brasil; j) tempo de moradia no Brasil; e k) acesso aos serviços de saúde.

\section{País de origem}

Ao analisar o contexto brasileiro, observa-se que os números relacionados a refugiados e migrantes são alarmantes. De acordo com um relatório emitido pelo Conare (2016), as solicitações de refúgio aumentaram $2.868 \%$ nos últimos cinco anos e o número de migrantes permanentes chegou a 400.006 em 2016. Entre esses indicadores, cabe destacar que o Rio Grande do Sul foi apontado como o estado que mais recebe refugiados e que haitianos e senegaleses são as nacionalidades mais recorrentes (Acnur, 2016).

Dados da Polícia Federal apontam que o Haiti é o terceiro país com maior entrada de migrantes no Brasil. Em 2016, 60,56 mil haitianos chegaram ao país. O Senegal aparece como o segundo país que mais solicita refúgio, sendo que o Haiti figura em primeiro lugar. Os números de solicitação de refúgio, em 2016, eram de 48.371 para o Haiti e 7.206 para o Senegal (Conare, 2016).

Em 2015, o Ministério da Justiça demonstrou que os principais fluxos migratórios no Rio Grande do Sul são compostos por sujeitos provenientes do Haiti, do Senegal e do Gana. Esses dados condizem com os encontrados neste trabalho. Sabe-se que a região metropolitana, onde a pesquisa foi realizada, conta com um grupo grande de haitianos e de senegaleses e que essas populações se diferem muito quanto à cultura, escolaridade e 
outras aspectos que serão analisados a seguir. Apesar desses dados, o maior número de entrevistados desta pesquisa tinha como país de origem o Senegal (11 participantes). Apenas dois dos entrevistados tinham como país de origem o Haiti e um a Costa do Marfim.

\section{Status legal no Brasil}

Entre os entrevistados, 10 denominaram-se migrantes e quatro refugiados. A questão do status aparece como algo importante e, ao mesmo tempo, conflituoso para os entrevistados. Foi possível perceber que muitas vezes o status aparece como uma forma de identidade para eles aqui no Brasil, pois é a partir dessa denominação que a população irá adquirir seu espaço e seus direitos de cidadãos. É importante ressaltar ainda que na análise das respostas foi considerado o status que o sujeito entrevistado referia ter, que não necessariamente é o mesmo apresentado nos documentos, dado que mostra um desconhecimento dos entrevistados sobre seu status legal.

Durante as entrevistas, muitos dos participantes mostraram-se confusos em relação ao seu status, visto que a grande maioria veio ao Brasil para trabalhar e não necessariamente saiu do país por alguma questão que configure o refúgio. Verificou-se que muitos têm o status de refugiado em seus documentos, mas, apesar disso, como vieram ao Brasil com o intuito de trabalhar, consideram-se migrantes econômicos.

Essa "confusão" causa certo incômodo para eles, visto que além de não conseguirem identificar seus direitos e seus papeis como cidadãos do Brasil, isso acaba ligando-os, muitas vezes, a uma imagem errônea. Isso ocorre especialmente com os senegaleses, porque, diferentemente do Haiti, o Senegal não tem passado por situações de guerra e de desastres naturais, mas muitas vezes os senegaleses recebem o status de refugiado. No entanto, isso não exclui o fato de a vida no país estar complicada. Nas falas dos participantes, percebe-se a intenção dos entrevistados em esclarecer sua situação no Brasil:

eles botaram nos protocolos "refugiado". Eu não posso falar que não sou isso porque a polícia federal botou isso no protocolo, mas vim 
para trabalhar, ganhar e voltar para o meu país. (K., comunicação pessoal, 2016).

Refugiado não, porque no Senegal não tem guerra. Eu vim para ajudar minha família. Lá no Senegal uma pessoa ajuda toda família, toda família mora junto, pai, mãe etc. Se uma pessoa trabalha, ajuda a sustentar as outras. Eu vim para o Brasil para trabalhar e pagar as contas de lá, escola, luz, casa. (L., comunicação pessoal, 2016).

Essa é uma questão que também interfere em vários outros aspectos da vida dos entrevistados, afinal, o documento é uma forma legal de reconhecer o indivíduo em sociedade. Portanto, pode-se pensar que, sem os devidos documentos, não só os aspectos legais desses sujeitos são afetados, mas também sua subjetividade. Situações como emprego e moradia acabam sendo prejudicadas pela falta dos documentos, questões que podem ser percebidas nos relatos dos participantes. Nas palavras do participante B.: "eu quero ter os documentos e papeis para poder ir visitar minha família e voltar". Outros entrevistados também falam sobre o tema:

Só o RNE [Registro Nacional de Estrangeiro], mas é difícil porque é coisa do governo. A gente precisa do RNE para poder sair do Brasil e ir ver nossa família, então gostaria de ter esse documento logo, porque daí quem quer ir visitar a família pode ir. Na verdade, tenho problema de documento, se continuar assim queria voltar, mas se o documento ficar fácil, daí eu até fico aqui, se for imigrante, é difícil para tentar alguma coisa. (J., comunicação pessoal, 2016).

Porque se você não tem o documento, eles não fazem a conta no banco, daí a gente acaba perdendo o trabalho. Nosso problema aqui é o RNE que todo senegalês quer ter. Viemos para trabalhar, mas também queremos voltar, pensa, eu tenho mulher e dois meninos, o 
último eu ainda não conheci. Quero voltar, mas tenho medo de voltar, porque se eu voltar não consigo vir de novo. (K., comunicação pessoal, 2016).

Nesse sentido, identifica-se a importância de um apoio jurídico a esses sujeitos, visto que existem muitas diferenças, principalmente legais, entre migrantes e refugiados. Muitos dos entrevistados apresentaram dúvidas sobre seu real status, sobre suas obrigações e seus direitos legais como cidadãos no Brasil. Corrobora esses dados uma pesquisa realizada com refugiados de São Paulo e Rio de Janeiro, que mostrou que $28,1 \%$ dessa população sofreu com a demora na confecção do Registro Nacional de Estrangeiro (RNE), fato que também apareceu na fala de alguns participantes da presente pesquisa (Moreira, 2014).

\section{Estado civil e configurações familiares}

A maioria dos entrevistados é casada (oito se declararam casados e seis solteiros), sendo que todos os casados mencionam ter deixado esposas no país de origem. Além das esposas, quatro participantes têm filhos que também permaneceram no país de origem. Pesquisas realizadas com migrantes oriundos do Senegal em Caxias do Sul mostram que, entre 2010 e $2014,35,24 \%$ eram casados e 50,97\% solteiros, dados que diferem dos encontrados neste estudo. Isso pode se dar pelo fato de que a população aqui entrevistada também conta com haitianos e também é uma população que está há menos tempo no Brasil (Herédia \& Pandolfi, 2015). A Figura 1 detalha a quantidade de filhos de cada entrevistado. O fato de a família estar longe aparece como um fator de sofrimento para os entrevistados e também demonstra certa ambivalência, visto que todos gostariam de estar perto de suas famílias, mas, ao mesmo tempo, estão no Brasil com o intuito de fornecer uma vida melhor para elas. Muitos relatos trazem a saudade como uma grande dificuldade, que normalmente é amenizada por conversas via redes sociais. Cabe destacar que um dos 
entrevistados indicou em sua resposta que não viu seu último filho nascer, pois já morava no Brasil e, portanto, o conhece apenas por meio de vídeo. Uma das características que diferencia a população senegalesa da haitiana, segundo Uebel (2015), é o fato de que os haitianos tendem a migrar mais com seus familiares do que os senegaleses, que tendem a migrar sozinhos ou, no máximo, com alguns amigos ou parentes de um grau menos formal, por exemplo, os primos.

Figura 1. Número de filhos

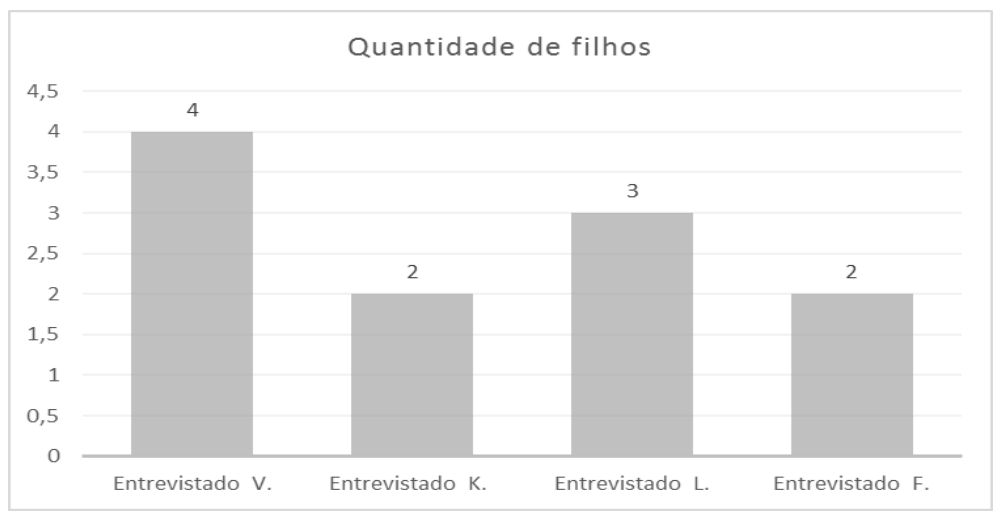

Fonte: Elaborada pela autora.

\section{Religião}

Sabe-se que culturalmente Haiti e Senegal têm diferenças significativas, sendo uma delas a religião. A maioria dos entrevistados (11) está vinculado à religião islâmica, os demais são adventistas (dois) e católico (um). Esse fato se dá especialmente porque o maior número de participantes é oriundo do Senegal, onde $95,40 \%$ da população é muçulmana; no Haiti, 3\% da população é adventista; o único católico entrevistado era da Costa do Marfim. Apesar de apresentarem hábitos culturalmente distintos, todos os entrevistados relatam sentirem-se acolhidos por igrejas e instituições ligadas às suas religiões. Além disso, citam que respeitam os hábitos brasileiros, mas que não podem e não irão "trair" sua religião. 0 art. $4^{\circ}$ da Convenção de Genebra, da qual o Brasil faz parte, afirma que: "Os Estados Membros proporcionarão aos refugiados em seu território um tratamento ao menos tão 
favorável quanto o que é proporcionado aos nacionais, no que concerne à liberdade de praticar a sua religião e no que concerne à liberdade de instrução religiosa dos seus filhos" (ONU, 1951, p. 5).

Portanto, na perspectiva dos entrevistados, entende-se que o Brasil tem sido acolhedor e receptivo para esses sujeitos no aspecto da religião. Isso se mostra muito importante devido ao papel e ao valor ético e moral que a religião desempenha na vida desses sujeitos.

Idioma

Todos os entrevistados falavam mais de um idioma, porque muitas vezes em seus países de origem já utilizam outras línguas e dialetos. Além disso, eles relatam aprender na escola outras línguas, como o inglês. O francês apareceu como um idioma comum a todos, como se pode ver na Figura 2. Apesar disso, normalmente a forma de comunicação utilizada por eles são os dialetos: o wolof é falado por senegaleses, e o crioulo é falado por haitianos. Um levantamento feito com haitianos residentes no Rio Grande do Sul mostrou que eles são hábeis para falar crioulo, espanhol, francês e português, já os senegaleses demonstram mais habilidade com os idiomas francês, inglês, espanhol e português, além dos dialetos locais do país de origem (Uebel, 2015).

Figura 2. Idioma 


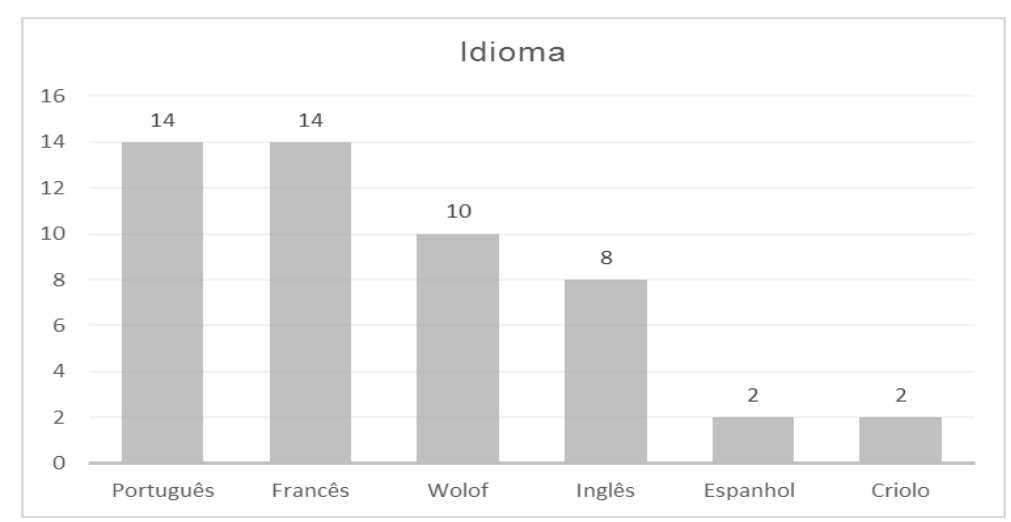

Fonte: Elaborada pela autora.

Quando questionados sobre quando foi o primeiro contato com a língua portuguesa, muitos deles relataram que foi ao chegar ao Brasil, como se pode observar na Figura 3, sendo que alguns dizem que nem sabiam, antes de chegar, que no Brasil fala-se português. Apenas dois entrevistados já haviam tido contato anterior com a língua. Ainda assim, todos eles mostraram-se bastante empenhados e dedicados ao aprendizado da língua, como podemos perceber na seguinte fala: "Eu aprendi sozinho na internet quando cheguei ao Brasil, lá eu tinha muita coisa para fazer e não deu tempo de aprender, quando cheguei vi que se eu quisesse trabalho precisava aprender português" (G., comunicação pessoal, 2016).

Figura 3. Primeiro contato com o português

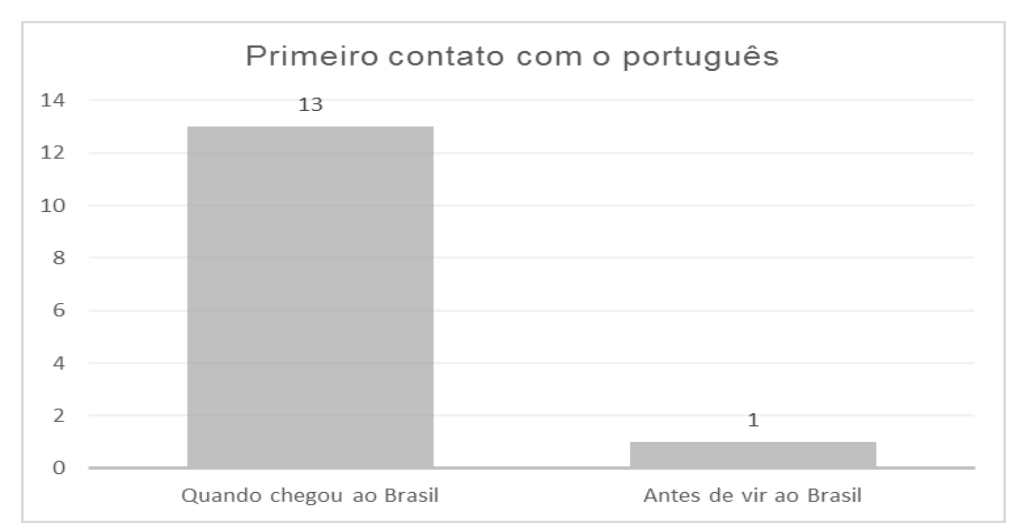

Fonte: Elaborada pela autora. 
Foi solicitado também que cada um dos entrevistados atribuísse uma nota ao seu nível de conhecimento na língua portuguesa. Eles deveriam classificar seu conhecimento de 1 a 10 , sendo que 1 significava "nenhum conhecimento" e 10 significava "domínio total do idioma". O resultado encontra-se na Figura 4.

Figura 4. Nota que atribui ao português

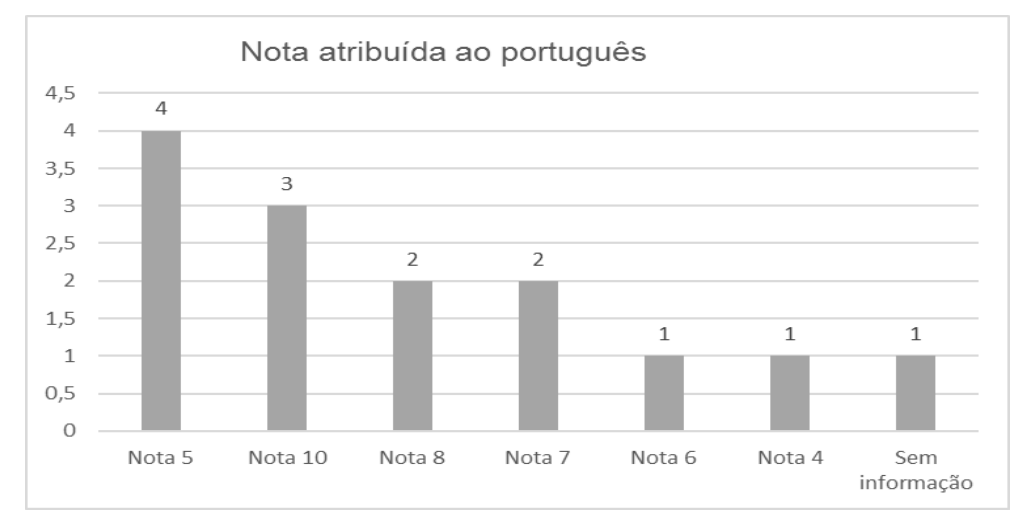

Fonte: Elaborada pela autora.

Pelas respostas, é possível perceber que a maioria acredita que seu aprendizado no idioma português está em um nível intermediário, com um desempenho possível de ser melhorado. Reforça-se aqui a importância da frequência nas aulas de português e da necessidade de ofertar esse tipo de aprendizagem de forma gratuita. Um estudo desenvolvido pelo Ministério da Justiça demonstrou que $89 \%$ dos migrantes entrevistados por uma pesquisa realizada em diversas regiões do Rio Grande do Sul relataram não ter tido 
acesso à educação no Brasil e 93,3\% referiram não ter sido possível contar com instituições públicas de educação, de acordo com o Instituto de Pesquisa Econômica e Aplicada (Ipea, 2015).

Esse certamente é um dos aspectos mais relevantes para os refugiados e migrantes. O idioma apareceu em diversas respostas como a maior dificuldade e como um fator que perpassa, consequentemente isso dificulta suas vidas em diversas áreas, como na inserção no trabalho, no lazer, na socialização e no acesso aos serviços públicos. Além disso, por não compreenderem o idioma, muitas vezes acabam perdendo oportunidades de emprego e ficam vulneráveis a situações nas quais podem ser enganados. A partir dos depoimentos, percebe-se como certas dificuldades acabam interferindo no dia a dia e nas atividades básicas:

O mais difícil aqui [no Brasil] é falar. (C., comunicação pessoal, 2016).

Tem muita vaga aqui, mas é complicado para senegalês, porque não entende o português e o que tem que fazer no serviço. Se ninguém ajudar, a gente nunca vai saber. (L., comunicação pessoal, 2016). Idioma, na verdade tudo, porque tudo depende da comunicação. Às vezes a gente vai no Sine [Sistema Nacional de Emprego], pega uma vaga mas perde, porque não conseguimos ler muito as placas. Alguns pegavam o trem errado, o ônibus errado... Meus amigos me contaram. Esta é uma dificuldade, quando eu cheguei também tive essa dificuldade de transporte. (J., comunicação pessoal, 2016).

Sendo assim, o idioma é um dos aspectos mais importantes, se pensarmos na integração social desses sujeitos. Aprender o idioma local ajuda a integração de diversas formas, entre elas: auxilia no desenvolvimento das relações interpessoais, auxilia nas questões profissionais e sociais com a sociedade receptora, fortalece a confiança e a 
segurança nas relações entre os indivíduos e possibilita mais facilidade no acesso aos serviços locais, como os de saúde e educacionais. Pode-se pensar também que a falta e/ou dificuldade na comunicação deixa esses sujeitos mais vulneráveis a situações de risco (Acnur, 2002, apud Silva, Lacerda, Jorgensen \& Fonseca, 2011).

\section{Cidade de residência atual}

Os dados apontaram que a maioria dos entrevistados reside na cidade de Novo Hamburgo (12), sendo que apenas dois estão morando em outras regiões (Porto Alegre e Canoas). Apesar disso, durante as entrevistas, percebeu-se que muitos deles já haviam residido em outras cidades da região metropolitana de Porto Alegre, da região da Serra do Rio Grande do Sul e até mesmo em países vizinhos do Brasil. As oportunidades de emprego foram citadas por eles como o motivo da mudança de cidade e país. Esse fato destaca a importância atribuída por esses sujeitos ao trabalho, pois a escolha da residência é diretamente influenciada pelas oportunidades de empregos em uma determinada região.

Segundo Herédia e Pandolfi (2015), muitos dos migrantes que residem na cidade de Caxias do Sul, no Rio Grande do Sul, escolheram a região como destino principalmente por ser um dos maiores polos industriais do estado. Além disso, a escolha dos migrantes por cidades não metropolitanas tem se dado devido às condições de acolhimento oferecidas.

\section{Escolaridade}

A escolaridade dos participantes foi um dos dados mais heterogêneos que apareceu nos resultados, o que pode ser analisado na Figura 5. Observaram-se diferenças significativas, sendo que alguns dos participantes não concluíram o ensino fundamental ou sequer frequentaram a escola, enquanto outros tinham ensino superior completo. 
Figura 5. Escolaridade

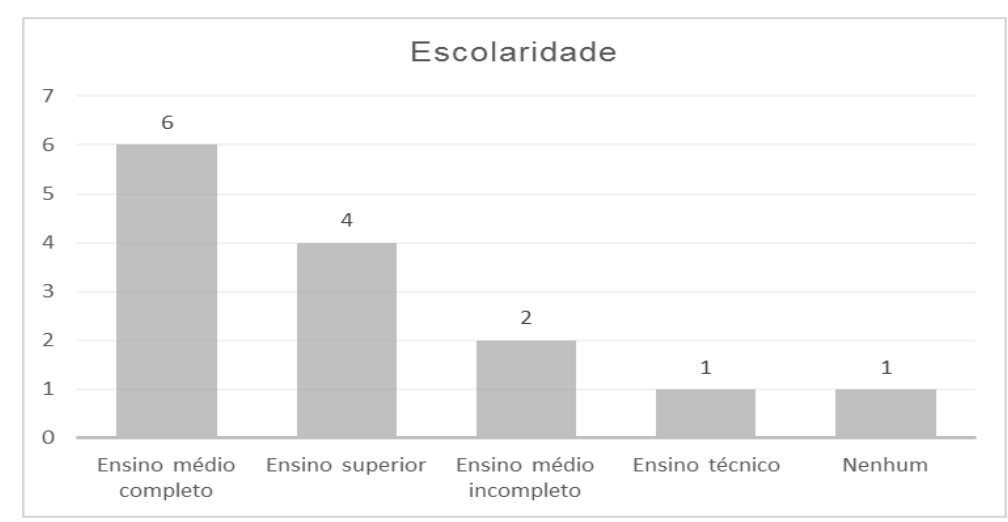

Fonte: Elaborada pela autora.

Estudos anteriores demonstram que o perfil dos migrantes senegaleses na Serra Gaúcha entre 2010 e 2014 era de $0,97 \%$ de analfabetos, $24,41 \%$ com ensino fundamental incompleto, 15,09\% com ensino fundamental completo, 13,52\% com ensino médio completo e 1,35\% com ensino superior completo. Na presente pesquisa, foi possível perceber que os entrevistados que referiam ter ensino médio completo e ensino superior eram, em sua maioria, haitianos. Segundo o Ministério do Trabalho (2011, apud Zeni \& Filippim, 2014), a maioria dos haitianos que chega ao Brasil tem ensino fundamental, médio e/ou fundamental incompleto; porém, já foram registrados sujeitos com ensino superior completo em busca de trabalho, mesmo que em áreas diferentes daquelas de suas formações (Herédia \& Pandolfi, 2015).

Cabe destacar a dificuldade em descrever a escolaridade dos participantes, especialmente dos senegaleses, pensando nos parâmetros brasileiros. Isso ocorre porque o sistema educacional no Senegal é organizado de maneira diferente do conhecido no Brasil. No Senegal, o ensino é baseado em um modelo francês, que tem três etapas: pré-escolar, ensino primário e ensino médio. A primeira etapa não é obrigatória, a segunda envolve crianças de 7 a 12 anos, e a última tem como objetivo dar continuidade ao período anterior e prioriza a capacidade dos alunos de observar, experimentar, investigar, sintetizar e criar, direcionando-os para alguma área de sua escolha. Dessa forma, pode-se pensar que 
existem diferenças não só culturais, mas também educacionais entre Senegal e Brasil, reforçando a importância de um cuidado ao tentar "encaixar" os cidadãos senegaleses aos padrões brasileiros (Herédia \& Pandolfi, 2015).

Percebe-se, pelo contato com a população de refugiados e migrantes, que existe uma grande demanda em relação à formação superior e/ou profissional, tanto daqueles que já têm algum tipo de formação quanto daqueles que pretendem iniciar alguma especialização no Brasil. Questões referentes à validação de diplomas, às possibilidades de trabalho no Brasil na área de formação, às qualificações profissionais necessárias e às formas de ingressar no ensino superior são algumas das principais dúvidas. Nota-se, na Figura 5, que quatro participantes afirmam ter ensino superior, já suas áreas de formação foram bastante variadas, sendo que muitas delas direcionam para profissões bastante populares no Brasil, como pode ser notado na Figura 6. Deve-se ressaltar que, na aplicação do questionário, quando foi perguntado se eles tinham alguma formação em seu país de origem, não foi solicitado que especificassem se era uma formação de ensino superior, técnica ou uma qualificação profissional, respeitando o que cada entrevistado considera como formação.

Figura 6. Área de formação

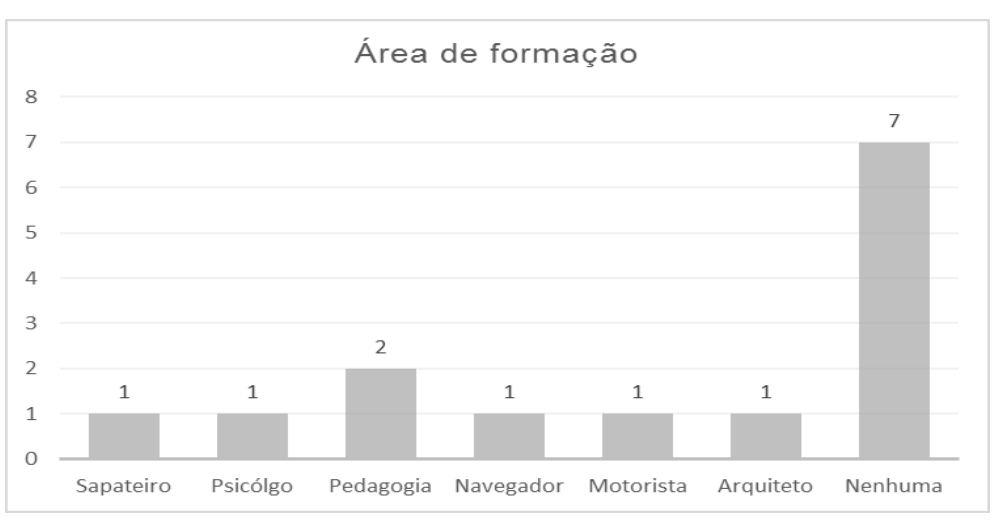

Fonte: Elaborada pela autora.

Pode haver diversos perfis de migrantes, no que diz respeito ao grau de instrução e área de formação. No caso deste estudo, os migrantes e/ou refugiados oriundos do Haiti 
apresentavam um grau de instrução maior do que os senegaleses, pois em sua grande maioria tinham alguma formação superior e ensino médio completo. Em contrapartida, outra pesquisa realizada com senegaleses e haitianos residentes no Rio Grande do Sul mostrou que $4,26 \%$ dos senegaleses tinham ensino superior e $0,04 \%$ dos haitianos tinham esse mesmo grau de instrução, dados que divergem dos encontrados no presente estudo. Deve-se considerar ainda que muitos deles - sejam senegaleses, sejam haitianos enquadram-se em outros níveis de instrução por terem cursos técnicos ou profissionalizantes (Sakho et al., 2015; Uebel, 2015).

\section{Ocupação no país de origem}

No que diz respeito às ocupações que os entrevistados tinham em seus países de origem, os dados também foram bastante heterogêneos. Percebe-se, na Figura 7, que a maioria das profissões desempenhada por eles em seus países poderia ser desempenhada aqui no Brasil, no entanto, não é isso que acontece.

Figura 7. Ocupação no país de origem

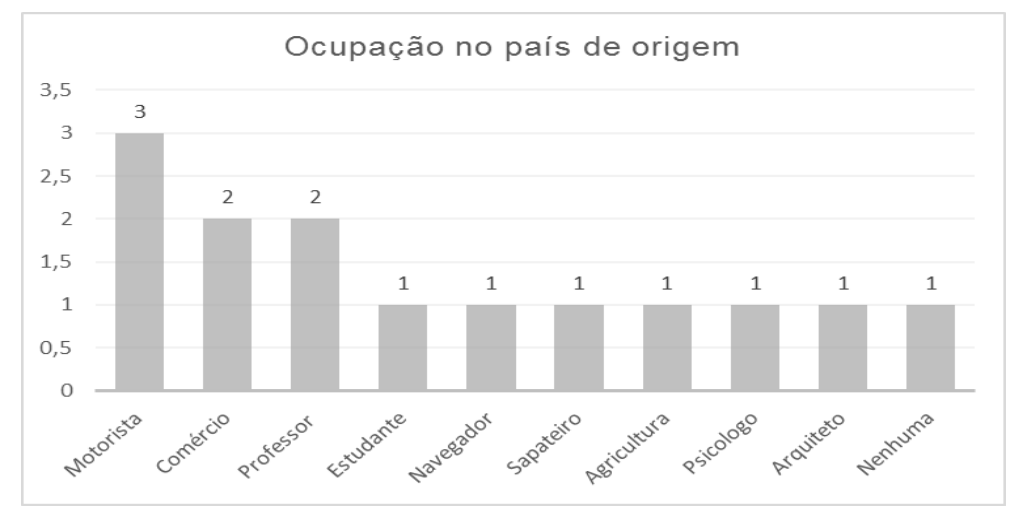

Fonte: Elaborada pela autora.

Uma pesquisa realizada em Caxias do Sul mostrou que os migrantes senegaleses que lá residem também apresentavam ocupações no país de origem similares às 
encontradas neste estudo. Apesar de a ocupação mais comum entre eles ter sido o trabalho como comerciante, outras atividades que exigem habilidades específicas, como motorista, sapateiro, pescador e agricultor, também apareceram no levantamento (Herédia \& Pandolfi, 2015).

A atividade profissional que mais se destacou foi a de motorista, fato que faz com que muitos deles tenham desejo de conseguir a carteira de habilitação brasileira. Muitos entrevistados trouxeram o desejo de praticar no Brasil as mesmas atividades profissionais que praticavam no país de origem. Para muitos é frustrante estar trabalhando em algo tão diferente e muitas vezes inferior às atividades que já desempenhavam em seus países.

\section{Ocupação no Brasil}

No momento da pesquisa, a maior parte dos participantes estava inserida no mercado de trabalho formal. No entanto, conforme alguns dados obtidos por este trabalho, percebe-se que muitos ainda têm carga horária excessiva e baixos salários.

Os campos e instituições em que estão inseridos são diversos, mas a maioria encontra-se em indústrias. Percebe-se que os entrevistados estão trabalhando em áreas muitas vezes desvalorizadas e rejeitadas pelos brasileiros, portanto, pode-se pensar que eles estão ocupando cargos com pouca visibilidade e com baixos salários. Observa-se na Figura 8 a atuação profissional dos entrevistados.

Figura 8. Ocupação no Brasil (dois entrevistados tinham duas ocupações)

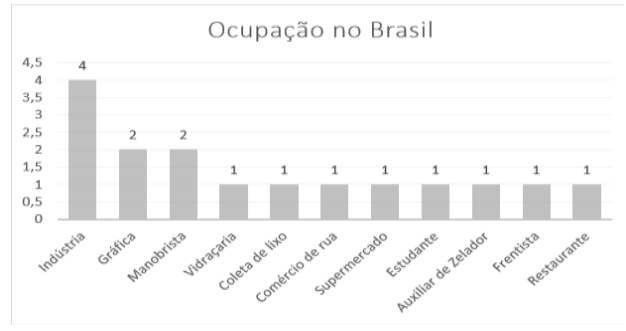

Fonte: Elaborada pela autora. 
Destaca-se que 13 entrevistados tinham vínculo formal de trabalho e apenas um estava sem emprego no momento. No entanto, a formalização não necessariamente garante que tenham seus direitos trabalhistas respeitados. Em relação ao salário, conforme indicado na Figura 9, a maioria dos entrevistados afirma receber entre um e dois salários mínimos, sendo que o salário mínimo no Brasil no momento da entrevista era de $\mathrm{R} \$ 880,00$ ("Salário Mínimo", 2016).

Figura 9. Renda mensal

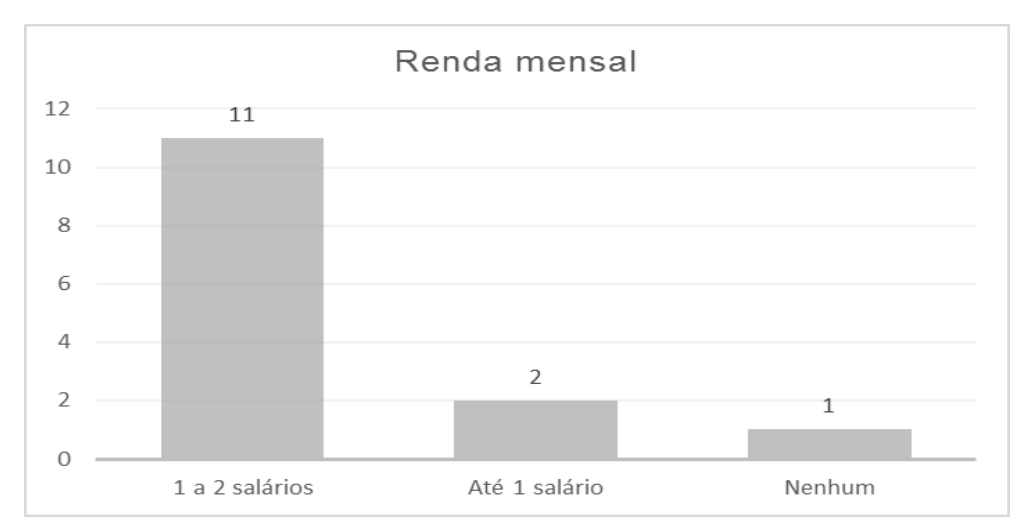

Fonte: Elaborada pela autora.

Durante as entrevistas ficou claro que a expectativa geral, antes de chegar ao Brasil, era de que os salários aqui seriam muito maiores do que realmente são e que o dinheiro recebido valeria mais em seus países. Com o valor que recebem, os participantes da 
pesquisa pagam o aluguel, as contas básicas (água, luz e internet), compram comida e enviam um valor para as suas famílias. Nas falas dos participantes, percebe-se essa questão de expectativa versus realidade.

Tem diferença no salário. Eu achei que ia ganhar um salário que ia valer muito lá no Senegal, mas não. Só dá pra comprar a comida lá, aqui não sobra nada. (K., comunicação pessoal, 2016).

Eu achava que o Brasil era melhor, mas não tem muita diferença. Aqui o dinheiro não é muito também. No mês não sobra nada, nada, nada de dinheiro, mando tudo para família, o aluguel lá é muito caro, mais caro que aqui, só o aluguel para minha esposa e filho são R\$700,00. Tenho dois irmãos que também têm família, então eles não podem ajudar a minha. (V., comunicação pessoal, 2016).

Tem diferença. Está difícil aqui, igual lá, né, achei que seria mais fácil, mas não. Quando nós recebemos nosso salário, pagamos nossas contas, não sobra quase nada para juntar dinheiro e para ajudar a família. Queria voltar com bastante dinheiro para ajudar nosso país, mas tudo bem. (J., comunicação pessoal, 2016).

Em outras pesquisas realizadas no Brasil com migrantes e refugiados, o padrão salarial aparece da mesma forma. Uebel (2015) relata que os haitianos que residem no Rio Grande do Sul recebem, em média, um salário mínimo, que chega a ser duas vezes maior do que o mínimo do Haiti; para senegaleses, esse valor chega a ser até quatro vezes maior do que o salário mínimo do Senegal. A pesquisa realizada com migrantes senegaleses em Caxias do Sul mostrou que a maioria dos migrantes $(24,48 \%)$ recebia entre dois e três salários mínimos, entre 2010 e 2014 , e que 53,18\% deles estavam sem renda (Herédia \& Pandolfi, 2015). Já em 2016, uma pesquisa mostrou que $91 \%$ dos migrantes que residem no sul do Brasil recebem até dois salários mínimos por mês, o que condiz com os dados 
encontrados nesta pesquisa (Ipea, 2015). Embora o salário mínimo no Brasil seja superior àquele recebido pelos participantes em seus países de origem, em função do alto custo de vida, eles relatam insatisfação em relação ao salário.

Tá complicado aqui no emprego, porque um Senegal ganha $\mathrm{R} \$$ $1.000,00$ e precisa comer, pagar aluguel e contas. As horas de serviço aqui são muito tempo. As pessoas lá no Senegal sabem como funcionam empregado, aqui não, as pessoas podiam ajudar mais. Aqui onde eu trabalho não tenho tanto problema. (L., comunicação pessoal, 2016).

Em relação à carga horária, a maioria dos participantes (10) relatou trabalhar oito horas diárias, enquanto quatro realizam mais de oito horas diárias. Alguns trabalham à noite e outros em horário comercial. Dois entrevistados trabalhavam em dois empregos diferentes e apenas um atuava no comércio informal de mercadorias (vendas na rua) nas horas vagas.

Uma pesquisa realizada com refugiados em São Paulo e Rio de Janeiro no ano de 2008 mostrou que $56,4 \%$ ( 230 casos) dos refugiados estava trabalhando; destes, $74,8 \%$ trabalhavam em uma empresa ou instituição exclusivamente privada; $32,8 \%$ tinham carteira assinada pelo empregador; e 52,2\% não tinham carteira assinada porque não eram empregados. Entre aqueles que estavam trabalhando, 14,8\% tinham um trabalho adicional. Já uma pesquisa realizada com migrantes no Rio Grande do Sul mostrou que $58 \%$ deles estavam trabalhando. Complementando, uma pesquisa realizada em 2007 com refugiados do Rio de Janeiro e São Paulo apontou que $32,8 \%$ dos participantes tinha carteira assinada (Aydos, Baeninger \& Dominguez, 2008; Ipea, 2015; Moreira, 2014).

Apesar de apresentarem algumas frustrações em relação ao trabalho, principalmente no que diz respeito ao salário, todos os participantes mostraram-se extremamente gratos por estarem trabalhando, visto que o trabalho tem um papel relevante em suas vidas. Da mesma forma, outros aspectos apareceram como favoráveis ao trabalho, como o fato de 
todos estarem trabalhando no setor formal com a carteira devidamente assinada e terem alguns outros benefícios, como plano de saúde.

Percebe-se que o trabalho influencia diretamente a permeância dos entrevistados no Brasil. Todos os participantes vieram ao Brasil em busca de oportunidades, especialmente de trabalho, visando enviar dinheiro para as famílias, que permaneceram em seus países, com o intuito de possibilitar a elas uma qualidade de vida melhor.

Entretanto, o trabalho também pode se apresentar como fator de risco à saúde dessa população, fazendo com que os indivíduos se submetam a diversas situações. Pode-se exemplificar isso com situações como: trabalhar em dois lugares diferentes, um durante o dia e outro à noite, resultando em uma carga horária excessiva; aceitar cargos diferentes dos que desejavam e do que estavam acostumados; submeter-se a situações de insegurança laboral por desconhecer o sistema trabalhista, o que pode resultar em casos de desigualdade e desrespeito.

\section{Tempo de moradia no Brasil}

A maioria dos entrevistados está no Brasil há mais de dois anos, conforme a Figura 10. Identificam-se, nas respostas, algumas diferenças entre os que estão há mais tempo no país, não só pelo fato de falarem o português melhor, mas também pela análise que fazem do período. Percebe-se que as pessoas que estavam há mais tempo no país já demonstravam uma certa "desilusão" em relação às expectativas e também certa consciência de seus planos futuros, conforme discussão a seguir. 
Figura 10. Tempo que reside no Brasil

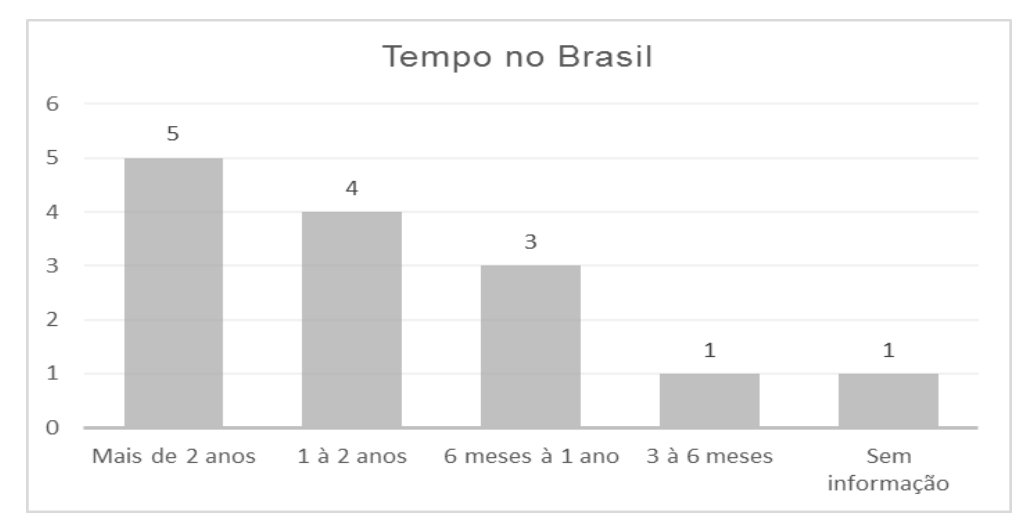

Fonte: Elaborada pela autora.

Os entrevistados que estão no Brasil há mais tempo expressam mais facilmente as dificuldades psicossociais enfrentadas, além disso, percebe-se uma crítica maior diante das situações que os deixam insatisfeitos e tornam-se uma espécie de referência para eles. Muitas dessas dificuldades foram percebidas não apenas nas entrevistas, mas também no contato no projeto de extensão.

\section{Acesso aos serviços de saúde}

Em relação ao acesso aos serviços de saúde, apenas dois participantes relataram não ter o cartão Sistema Único de Saúde (SUS), mas todos sabiam da necessidade e da existência do cartão. Observa-se, no entanto, que o fato de possuírem o cartão não garante necessariamente o acesso aos serviços de saúde, visto que muitos deles desconhecem os serviços disponíveis, os locais onde podem ser atendidos e os direitos que têm.

Em uma pesquisa realizada com migrantes do Rio Grande do Sul, $72 \%$ dos entrevistados relataram não ter tido acesso aos serviços de saúde e $84 \%$ relataram que não conseguiram contar com as instituições públicas de saúde. Em contrapartida, em São Paulo e no Rio de Janeiro, 51,3\% dos refugiados referiram procurar o hospital mais próximo de casa para serem atendidos (Ipea, 2015; Moreira, 2014).

Segundo Moura (2016), quando falamos em questões relacionadas à educação, 
saúde e moradia de migrantes e refugiados, os documentos e leis brasileiras demonstramse muito superficiais, ocasionando uma falta de compromisso do Estado e, consequentemente, uma falha na garantia de direitos. Apesar disso, nesta pesquisa alguns dos entrevistados relataram já ter acessado o serviço médico do SUS, e outros, que têm plano de saúde pago pelas empresas onde trabalham, também já haviam utilizado os serviços de saúde. De forma geral, os entrevistados relataram ter sido bem atendidos quando precisaram, apenas com algumas dificuldades para esperar o atendimento e para ser compreendido. Isso pode ser percebido nas seguintes falas dos participantes:

Sim, já usei, não foi muito bem atendido, pois o pessoal não entendia, difícil para explicar. Não fui muito bem tratado, fizeram do jeito que fazem com os brasileiros [risos]. (H., comunicação pessoal, 2016).

Eu tenho cartão do SUS, fui lá no hospital uma vez, daí eles falaram que sem cartão não podia consultar, fui vacinar. Agora tem plano de saúde [pela empresa]. (L., comunicação pessoal, 2016).

Apesar disso, deve-se pensar que o fato de os sujeitos conhecerem os serviços e o cartão do SUS não garante, na prática, que seus direitos sejam atendidos, principalmente por não haver políticas públicas específicas para o atendimento dessa população. Alguns dos entrevistados acreditam que a saúde seja melhor do que em seus países, já outros divergem e relatam sentir discriminação no momento de ser atendido:

Eu gostei da saúde, não é tanto diferente do meu país, mas aqui tem muito hospital. (C., comunicação pessoal, 2016).

Se tu for lá no hospital falar que tem um problema, eles vão te dar atestado de um dia, daí tu não pode faltar trabalho, só porque é senegalês. Se tu [referindo-se à entrevistadora] for no hospital, eles 
vão te dar atestado de três dias. (B., comunicação pessoal, 2016).

Por priorizarem o trabalho, a saúde não aparece como algo muito relevante para os entrevistados. Como sociedade, é comum acreditar que os migrantes e refugiados são pessoas saudáveis, pois são fortes e resistentes em suas trajetórias e ainda têm muita força para o trabalho, por outro lado, algumas pessoas os enxergam como portadores de doenças que ameaçam a saúde pública do resto dos habitantes da cidade para onde migram. Todavia, nenhum desses olhares interpreta o migrante/refugiado como uma pessoa, para quem a saúde é um aspecto muito importante. São vários elementos que influenciam a vida desses sujeitos, por exemplo, o estresse do trabalho em excesso, a adaptação à nova sociedade, a viagem que pode implicar situações de risco, a saudade da família e de casa e as dificuldades cotidianas (Padilla, 2013).

Consequentemente, pensar no processo de integração dos migrantes e refugiados demanda um olhar para a saúde desses sujeitos, pelo simples fato de que é algo que se manifesta em todos os aspectos da vida. Nessa perspectiva, a saúde transcende amplamente o tema da doença e aponta para inúmeras situações, que vão desde as ações para promoção da saúde e de prevenção da doença, o acesso aos serviços e cuidados de saúde, o tratamento e a reabilitação até a acessibilidade linguística, cultural e material (Padilla, 2013).

Apesar de terem seus direitos assegurados na Constituição Federal e nos Diretos Humanos, muitas vezes os migrantes e refugiados encontram problemas para acessar os serviços de saúde. Todos os estrangeiros que se encontram no Brasil têm garantido, ou ao menos deveriam ter, o atendimento nos hospitais públicos. O Acnur viabiliza uma verba para a compra de medicamentos e os destina às Organizações não Governamentais (ONGs), responsáveis por avaliar as necessidades de uso dos fármacos. Há ainda uma preocupação com o atendimento psicológico - o Conare viabiliza uma verba para um programa de saúde mental (Bezerra, 2013).

Perante a falta de ação do Estado, a sociedade civil tem assumido muitas 
responsabilidades e ações com o intuito de preencher as lacunas, faltas e omissões estatais. No entanto, as dificuldades financeiras também afetam as ações das organizações (ONGs, caritas, instituições religiosas, associações e fundações). De forma geral, essas organizações têm desenvolvido intervenções, também no âmbito da saúde, desde fornecer informações sobre direitos, acesso à saúde, prestação de alguns serviços específicos e até apoio sociojurídico, quando necessário (Padilla, 2013).

\section{Considerações finais}

O presente trabalho buscou compreender quais são as principais demandas no campo dos direitos humanos e da integração social de migrantes e refugiados residentes no Vale dos Sinos. Isso se deu pela caracterização da população de migrantes e refugiados, discussão das principais dificuldades encontradas por migrantes e refugiados e pelos fatores que contribuem com a integração social desse público.

Pelos resultados, percebe-se que, além do fato de esses sujeitos estarem enfrentando diversas dificuldades no Brasil, isso está refletindo no seu processo de integração social. Sabe-se que, incialmente, a integração se dará a partir da aquisição de documentos fundamentais, do trabalho e estudo, do acesso à saúde e da interação cultural. No entanto, raramente esses sujeitos conseguem atingir todos esses aspectos ao chegar ao Brasil, tendo muitas vezes seus direitos humanos violados (Bógus \& Rodrigues, 2011 ).

Sendo essas as principais dificuldades que, consequentemente, dificultam a integração social, pensa-se na importância da criação de programas de acolhimento, mas principalmente na criação de políticas públicas para essa população ou no acesso àquelas já existentes. É necessário que se desenvolvam estratégias para dar visibilidade a essa população e assegurar-lhe os seus direitos. Além disso, no momento da integração, é preciso considerar que o sujeito ainda está fragilizado pelas experiências vividas no seu processo de fuga, portanto, sua subjetividade deve ser levada em consideração, principalmente no que diz respeito ao sentimento de desamparo (Instituto Adus, 2016). 


\section{Referências}

Alto Comissariado das Nações Unidas para Refugiados. (2016). Acnur: deslocamento forçado atinge recorde global e afeta 65,3 milhões de pessoas. Recuperado em 12 agosto, 2016, de https://nacoesunidas.org/acnur-deslocamento-forcado-atingerecorde-global-e-afeta-653-milhoes-de-pessoas/.

Alto Comissariado das Nações Unidas para Refugiados. (2017). Direitos e deveres dos solicitantes de refúgio e refugiados no Brasil. Brasília: Acnur.

Aydos, M., Baeninger, R., \& Dominguez, J. A. (2008). Condições de vida da população refugiada no Brasil: trajetórias migratórias e arranjos familiares. III Congresso da Associação Latino Americana de População. Córdoba, Argentina. Recuperado em 29 agosto, 2017, de http://bit.ly/2VXSDuE.

Baldin, N., \& Munhoz, E. M. B. (2011). Educação ambiental comunitária: uma experiência com a técnica de pesquisa snowball (bola de neve). Revista Eletrônica do Mestrado em Educação Ambiental, 27, 46-60. doi: https://doi.org/10.14295/remea.v27i0.3193.

Bezerra, M. T. (2013). O refúgio e a proteção dos direitos humanos no Distrito Federal: um estudo sob a perspectiva das políticas públicas. Dissertação de mestrado, Centro Universitário Unieuro, Brasília, Brasil. Recuperado em 4 abril, 2017, de http://www.unieuro.edu.br/mestradocienciapolitica/images/Dissertacoes/2013/Disse rtaao\%20Maria\%20Telma.pdf.

Bógus, L. M. M., \& Rodrigues, V. M. (2011). Os refugiados e as políticas de proteção e acolhimento no Brasil: história e perspectivas. Dimensões, 27, 101-114. Recuperado em 10 agosto, 2016, de http://www.periodicos.ufes.br/dimensoes/article/view/2585/2081.

Comitê Nacional para os Refugiados. (2016). Sistema de refúgio brasileiro: desafios e perspectivas. Recuperado em 20 março, 2017, de http://bit.ly/2KS6y4k. 
Creswell, J. W. (2010). Projeto de pesquisa: métodos qualitativo, quantitativo e misto (3a ed.). Porto Alegre: Artmed.

Gil, A. C. (2002). Como elaborar projetos de pesquisa (4a ed.). São Paulo: Atlas.

Gonçalves, A. J. (2001). Migrações internas: evoluções e desafios. Revista Estudos Avançados, 15(43), 173-184. doi: http://dx.doi.org/10.1590/S010340142001000300014 .

Herédia, V. B. M., \& Pandolfi, B. (2015). Migrações internacionais: o caso dos senegaleses em Caxias. In V. B. M. Herédia (Org.). Migrações internacionais: o caso dos senegaleses no sul do Brasil (pp. 95-113). Caxias do Sul: Belas-Letras.

Instituto Adus. (2016). Refugiado e Psicologia: a experiência da fuga e da reintegração no estrangeiro. Recuperado em 20 agosto, 2016, de http://bit.ly/21JOt60.

Instituto de Pesquisa Econômica e Aplicada. (2015). Migrantes, apátridas e refugiados: subsídios para o aperfeiçoamento de acesso a serviços, direitos e políticas públicas no Brasil. Brasília: Ministério da Justiça, Secretaria de Assuntos Legislativos, Ipea.

Laville, C., \& Dionne, J. (1999). A construção do saber: Manual de metodologia da pesquisa em Ciências Humanas. Porto Alegre: Artmed.

Lei n. 9.474, de 22 de julho de 1997. (1997). Define mecanismos para a implementação do Estatuto dos Refugiados de 1951, e determina outras providências. Recuperado em 12 junho, 2018 , de http://www.planalto.gov.br/ccivil_03/Leis/19474.htm.

Moreira, J. B. (2014). Refugiados no Brasil: reflexões acerca do processo de integração local. REMHU - Revista Interdisciplinar da Mobilidade Humana, 43, 85-98. Recuperado em 8 agosto, 2016, de http://www.scielo.br/pdf/remhu/v22n43/v22n43a06.pdf.

Moreira, V., \& Gomes, C. M. (Coord.). (2012). Compreender os Direitos Humanos: Manual de educação para os Direitos Humanos (3a ed.). Graz: European Training and Research 
Centre for Human Rights and Democracy (ETC).

Moura, C. S. B. (2016). Crise humanitária de refugiados: obstáculos e desafios existentes no Brasil. Recuperado em 20 abril, 2017, de http://repositorio.asces.edu.br/handle/123456789/188.

Organização das Nações Unidas. (1951). Convenção de Genebra relativa ao Estatuto dos refugiados. Recuperado em 12 agosto, 2016, de http://www.acnur.org/t3/portugues/recursos/documentos.

Padilla, B. (2013). Saúde dos imigrantes: multidimensionalidade, desigualdades e acessibilidade em Portugal. REMHU - Revista Interdisciplinar da Mobilidade Humana, 40, 49-68. doi: http://dx.doi.org/10.1590/S1980-85852013000100004.

Pussetti, C., \& Brazzabeni, M. (2011). Sofrimento social: idiomas da exclusão e políticas do assistencialismo. Etnográfica, 15(3), 467-478. doi: 10.4000/etnografica.1036.

Sakho, P., Diop, R., Mboup, B., \& Diadiou, D. (2015). A emigração internacional senegalesa: das casas no campo às cidades litorâneas. In V. B. M. Herédia (Org.). Migrações internacionais: o caso dos senegaleses no sul do Brasil (pp. 23-48). Caxias do Sul: Belas-Letras.

Salário Mínimo 2016 será de R\$888. (2015). Salário Mínimo. Recuperado em 5 maio, 2017, de https://meusalario.net/salario-minimo-2016.html.

Silva, W. M., Lacerda, F., Jorgensen, N., \& Fonseca, F. E. (2011). Diversidade cultural e a integração de refugiados: Simulação das Nações Unidas para Secundaristas (10a ed.). Brasília: SINUS.

Uebel, R. R. G. (2015). Análise do perfil socioespacial das migrações internacionais para o Rio Grande do SuI no início do século XXI: redes, atores e cenários da imigração haitiana e senegalesa. Dissertação de mestrado, Universidade Federal do Rio Grande 
do Sul, Porto Alegre, Brasil. Recuperado em 8 abril, 2017, de http://www.lume.ufrgs.br/handle/10183/117357.

Zeni, K., \& Filippim, E. S. (2014). Migração haitiana para o Brasil: acolhimento e políticas públicas. Pretexto, 15(2), 11-27. doi:

http://dx.doi.org/10.21714/pretexto.v15i2.1534.

Recebido em: 17/4/ 2018

Aprovado em: $27 / 1 / 2020$ 